\title{
Commentary \\ 'Old' Territorial Disparities and 'New' Spatial Patterns: Unraveling the Latent Nexus between Sustainable Development and Desertification Risk in Italy
}

\author{
Rosanna Salvia $^{1}\left(\mathbb{D}\right.$, Andrea Colantoni $^{2}$ (D), Leonardo Bianchini ${ }^{2} \mathbb{D}$, Gianluca Egidi ${ }^{2}$, Gloria Polinesi ${ }^{3}$, \\ Luca Salvati $^{4, *}$ and Giovanni Quaranta ${ }^{1}$ (D)
}

1 Department of Mathematics, Computer Science and Economics, University of Basilicata, Viale dell'Ateneo Lucano, I-85100 Potenza, Italy; rosanna.salvia@unibas.it (R.S.); giovanni.quaranta@unibas.it (G.Q.)

2 Department of Agricultural and Forestry Sciences (DAFNE), University of Tuscia, Via S. Camillo De Lellis snc, I-01100 Viterbo, Italy; colantoni@unitus.it (A.C.); l.bianchini@unitus.it (L.B.); egidi.gianluca@unitus.it (G.E.)

3 Department of Social and Economic Sciences, Polytechnic University of Marche, Piazzale Martelli 8, I-60121 Ancona, Italy; g.polinesi@univpm.it

4 Department of Economics and Law, University of Macerata, Via Armaroli 43, I-62100 Macerata, Italy

* Correspondence: luca.salvati@unimc.it; Tel.: +39-06-61-57-10

check for updates

Citation: Salvia, Rosanna, Andrea Colantoni, Leonardo Bianchini, Gianluca Egidi, Gloria Polinesi, Luca Salvati, and Giovanni Quaranta. 2022. 'Old' Territorial Disparities and 'New' Spatial Patterns: Unraveling the Latent Nexus between Sustainable Development and Desertification Risk in Italy. Economies 10: 50. https://doi.org/10.3390/ economies10020050

Academic Editors: Andrea Appolloni and Ralf Fendel

Received: 9 December 2021

Accepted: 6 February 2022

Published: 16 February 2022

Publisher's Note: MDPI stays neutral with regard to jurisdictional claims in published maps and institutional affiliations.

Copyright: (c) 2022 by the authors Licensee MDPI, Basel, Switzerland. This article is an open access article distributed under the terms and conditions of the Creative Commons Attribution (CC BY) license (https:// creativecommons.org/licenses/by/ $4.0 /)$.

\begin{abstract}
Although sustainable development and desertification risk are hegemonic concepts in environmental economics, their intimate relationship was occasionally studied and made spatially explicit. The present study contributes to fill this knowledge gap by delineating a statistical procedure that investigates, at the municipal scale in Italy, the association between two composite indexes of sustainable development (SDI) and desertification risk (ESAI). Based on a refined knowledge of the local context, results of a geographically weighted regression delineate two distinctive territorial models reflecting the mutual interplay of sustainable development and desertification risk in Italy. The level of sustainable development was negatively associated with desertification risk in Southern Italy, a region classified as 'affected' based on the Italian National Action Plan (NAP) to combat desertification. These findings document a traditional 'downward spiral' between local development and early desertification processes, suggesting that a high desertification risk is associated with local contexts having structural conditions that lead to unsustainable development, e.g., population growth, industrial development, tourism pressure, crop intensification, agricultural mechanization, and land abandonment. In non-affected regions such as Northern and Central Italy, the level of sustainable development was positively associated with desertification risk, indicating that sustainability conditions can be unable, at least in some local contexts, to assure a significant containment of environmental degradation. Policy strategies reconnecting local development with more specific environmental conservation targets in development countries are increasingly required to adapt to (and differentiate on the base of) heterogeneous local contexts.
\end{abstract}

Keywords: composite indexes; geographically weighted regression; sustainability; agricultural intensification; Italy

JEL Classification: Q5; R10; R14

\section{Introduction}

Sustainable development and desertification risk are recognized as hegemonic concepts in both ecological and socioeconomic disciplines (Dasgupta et al. 2006; Kahuthu 2006; Chelleri et al. 2015). However, their intimate relationship - at different geographical and temporal scales-was occasionally investigated and made spatially explicit, likely because a hardly distinguishable mix of biophysical and socioeconomic drivers is responsible for land degradation processes in advanced economies, making the joint assessment of desertification risk and sustainable development a particularly complex task (Tschakert 2007; Romm 
2011; Smiraglia et al. 2016; Sterk and Stoorvogel 2020). The role of human factors in early desertification processes is evident only in specific conditions with regional disparities, economic backwardness, and characteristic 'socially locked' communities (Boardman et al. 2003; Portnov and Safriel 2004; Iosifides and Politidis 2005; Benassi et al. 2020). Human activities that stimulate desertification risk include unsustainable farm practices (overgrazing, excessive use of chemicals, mechanization), heavy industry and mining, deforestation, overexploitation and contamination of water and other natural resources, urbanization and a generalized increase in artificial surfaces. At the same time, sustainable developmentintended as an appropriate and flexible response to socio-environmental stimuli-is a target that cannot be completely realized in some local contexts (Wilson and Juntti 2005; Imeson 2012; Kirkby 2021).

The complexity of the 'sustainability' concept represents a limitation for monitoring, modelling, and projection approaches (Kok et al. 2004; Galeotti 2007; Cavlovic et al. 2000; Akhtar-Schuster et al. 2017; Cecchini et al. 2019). Quantitative approaches that overpass traditional disciplinary boundaries (e.g., separating environmental science from socioeconomic studies) and focus on the spatially varying local contexts were appropriate to delineate dynamic patterns and complex relationships in (evolving) socio-ecological systems (Munasinghe 1999; Salvati and Zitti 2007; Wessels et al. 2007; Warner 2010). A refined profile of local communities contributes to ascertain the latent socioeconomic patterns and processes at the base of desertification risk in developed countries (Esposito et al. 2016; Wolff et al. 2018; Zambon et al. 2018; Destek and Sarkodie 2019). Although there is a strong interest on this issue from both research and policy perspectives (Franceschi and Kahn 2003), relatively few studies have investigated the relationship between desertification risk and sustainable development of local communities with a multidimensional perspective (Dumanski et al. 1998; Anselin 2001; Marston et al. 2005; Ali et al. 2007; Heidkamp 2008). On the contrary, thanks to the multidimensionality of both concepts, an integrated approach based on composite indexes may better explore latent spatial patterns and trends of the key factors affecting sustainability over an enough large spatial coverage (Rupasingha et al. 2004; Maddison 2006; Chimeli 2007; Zuindeau 2007; Yamamoto 2008).

The intrinsic complexity of local contexts is often the result of the millenary interaction between men and nature, outlining the mutual interplay of demographic, economic, political, social, and cultural forces (Boyce 1994; Barrett and Graddy 2000; Fingleton 2016; Sannigrahi et al. 2020). Consensus exists on the definition of Mediterranean-like ecosystems as 'hotspots' for global change, because of climate warning, land-use transformations, and the consequent pressure on natural habitats and biodiversity (Kok et al. 2004; Barbayiannis et al. 2011; Kairis et al. 2013; Egidi et al. 2021). In Mediterranean Europe-a well-studied, global hotspot of land degradation-urbanization, late industrialization, infrastructural expansion, tourism development, and agricultural intensification are important factors at the base of early desertification processes (Marathianou et al. 2020; Patel et al. 2007; Karamesouti et al. 2015; Recanatesi et al. 2016). A sustainable development path should mitigate the negative outcomes of these processes, balancing the economic impact of both intensification and extensivation of land resources' exploitation (Hubacek and van den Bergh 2006; Cerdà et al. 2010; Corbelle-Rico et al. 2012; Ciommi et al. 2018). The present study hypothesizes a relationship between sustainable development and desertification depending on local contexts that should be extensively considered in policy strategies integrating socioeconomic sustainability and environmental conservation targets (Biasi et al. 2015; Kairis et al. 2015; Kosmas et al. 2016).

Distinguishing different territorial levels of risk based on the Italian National Action Plan (NAP) to combat desertification (Zambon et al. 2017) and relating their spatial distribution with general conditions for sustainable or unsustainable development, are appropriate steps contributing to a wider knowledge of (apparent and latent) patterns and mechanisms underlying local sustainability. The intrinsic dimensions and determinants of local sustainability - and especially the environmental pillar-were more occasionally studied than other processes characteristic of the hegemonic concept of 'sustainable development'. 
Refined results in this direction may inform more effective strategies promoting a fine tuning between sustainable development and environmental issues that require an integrated (socioeconomic and ecological) policy response. We assumed local communities and the related territorial context as multifaceted dimensions affecting sustainable development and ecological degradation together (Wang et al. 2006; Wolff et al. 2018; Perrin et al. 2018; Rodrigo-Comino et al. 2021). More specifically, we investigate the local-scale relationship between sustainable development and desertification risk with a national coverage using geographically weighted regression models (Fotheringham et al. 2002). Using two standard (widely documented and policy relevant) indexes of sustainable development (Salvati and Carlucci 2014) and desertification risk (Delfanti et al. 2016), the present study proposes a spatially explicit, static assessment of the recent sustainable development path in Italian local communities-evolving between economic growth and environmental degradation (Salvati and Zitti 2008). This approach was considered suitable to depict multiple dimensions of sustainability in rapidly changing societies and economies (Gisladottir and Stocking 2005; Gavalas et al. 2014; Rontos et al. 2016; Salvati and Serra 2016). Italy has been selected as the case study because it is characteristic of different-often polarizedsocioeconomic and environmental contexts (Helldén and Tottrup 2008; Salvati and Zitti 2009; Briassoulis 2011; Colantoni et al. 2015). The use of composite indexes allows for an objective assessment of the local contexts under (more or less) sustainable development paths and exposed to a (more or less) evident risk of desertification (Halbac-Cotoara-Zamfir et al. 2020). Results can be used as an informative base to implement sustainability policies in developed and emerging countries characterized by important disparities in economic and social conditions.

\section{Methodology}

\subsection{Study Area}

Italy is a Mediterranean country covering $301,330 \mathrm{~km}^{2}$ of land with mixed topography (23\% flat, $42 \%$ hilly, 35\% mountainous: (Salvati et al. 2008)). Northern Italy is one of the most developed regions in Europe and occupies the whole Po valley (Recanatesi et al. 2016). Central Italy, separated from Northern Italy by the Apennines Mountain chain, is a polarized region with a marked urban-rural divide (Smiraglia et al. 2016). Southern Italy, together with Sicily and Sardinia, is a disadvantaged region with an economic structure centered on low- and medium-income agriculture and traditional tertiary activities, including construction, commerce, and the public sector (Zambon et al. 2017). Italy shows relevant disparities in population density and growth, settlement form and density, crop intensity, and tourism concentration, with impact on the distribution of natural resources (Delfanti et al. 2016).

\subsection{Evaluating the Level of Sustainable Development in Italian Municipalities}

To evaluate the level of sustainable development in Italy, we adopted an index of sustainable development (hereafter SDI) proposed in Salvati and Carlucci (2014) and made available at 8101 municipalities in Italy composing 99 variables from official statistics (Istat). Variables' selection, procedures for the explicit composition of elementary variables into basic indicators, and the identification of relevant, broad themes (6) and more detailed dimensions (14) composing the final index were detailed in Salvati and Carlucci (2014) following earlier studies for Italy, e.g., Ronchi et al. (2002). The considered variables provide a broad qualification of the economic structure, social traits, and environmental characteristics observed in the Italian municipalities (Abu Hammad and Tumeizi 2012). The construction of the composite index consisted of five steps: variable selection, data transformation, multivariate statistical analysis, weight derivation, and indicators' composition, controlling for the impact of different data transformation methodologies and variables' weighting schemes (Yli-Viikari et al. 2007; Nourry 2008; Siche et al. 2008; Zhou et al. 2010). The ability of the SDI to discriminate among different levels of sustainable development in the Italian municipalities was tested by correlating the composite index 
scores with semantically similar (but operationally independent) indicators made available at different spatial scales (Gidding et al. 2002; Niemeijer 2002; Nader et al. 2008; Khatun 2009). The final SDI ranges between 0 and 1; higher values are associated with sustainable development and was mapped with the aim of illustrating the ranking of each Italian municipality.

\subsection{Estimating the Level of Desertification Risk in Italian Municipalities}

We adopted the ESA (Environmentally Sensitive Areas) framework, one of the most widely used schemes quantifying land characteristics and sensitivity in Europe, Northern Africa, and the Middle-East (e.g., Kosmas et al. 2003; Bajocco et al. 2012; Ferrara et al. 2016, 2020; Huang et al. 2020) as an appropriate information system estimating the level of desertification risk in Italian municipalities. More recently, the ESA scheme was adopted to estimate global land sensitivity at a particularly detailed spatial resolution $\left(1 \mathrm{~km}^{2}\right)$ for that geographical coverage (Ferrara et al. 2020). The operational scheme calculates an index (hereafter, the ESAI) composing three dimensions (climate quality, soil quality, vegetation/land-use quality). Flexibility in the analysis of input variables and simplicity of land classification based on few, distinctive levels of risk that can be easily observed and validated on the ground are the main advantages of the ESA (Rodrigo-Comino et al. 2018; Salvati et al. 2012; Martínez-Valderrama et al. 2020). The outcomes of the ESA model have been extensively tested on the field at several local sites and in regional assessment exercises carried out in Spain and Italy documenting, in all cases, how the ESAI is an honest proxy of desertification risk (see an extensive review in (Ferrara et al. 2020)).

Information sources and technical details of ESAI construction for Italy were provided in earlier studies by Salvati and coworkers (Delfanti et al. 2016; Recanatesi et al. 2016; Smiraglia et al. 2016; Zambon et al. 2017). Climate quality was assessed considering three elementary variables: annual rainfall rate (long term average), aridity index (UNEP definition), and aspect (Salvati et al. 2008). Soil quality incorporated four variables: soil depth and texture, slope, and the nature of the parent material (Colantoni et al. 2015). Vegetation quality was evaluated through four variables: plant cover, fire risk, protection offered by vegetation against soil erosion, and the degree of resistance to drought shown by plants (Kairis et al. 2015). These variables were independent from those composing the SDI. A scoring system ranging from 1 (the lowest contribution to land degradation) to 2 (the highest contribution to land degradation) was applied to each variable based on the known relationship with land degradation processes and exposure to desertification risk (Salvati and Zitti 2007) following the benchmarking system introduced by Salvati and Zitti (2009). Partial indicators of climate (Climate Quality Index, CQI), soil (Soil Quality Index, SQI), and vegetation (Vegetation Quality Index, VQI) were estimated as the geometric mean of the different scores assigned to each input variable assigned to that quality (Salvati and Zitti 2008). As detailed above, each indicator ranges from 1 to 2 . The ESAI was then estimated at each elementary spatial domain as the geometric mean (equal weighting) of the quality indicators (CQI, SQI, VQI) obtaining a score ranging from 1 (the lowest risk) to 2 (the highest risk). The ESA score for each municipality was made homogeneous with the SDI by subtracting 1 from the original value and thus obtaining ESAI scores ranging from 0 to 1 , with desertification risk associated with higher score values. A Supplementary File provided additional materials and technical details assuring a more complete description of the ESA approach.

\subsection{Spatially Explicit Regression Models}

Assuming degradation processes' claim for response at different scales compared to those characterizing local development strategies (Wang et al. 2006), a refined understanding of the spatial variability related to the sustainable development-desertification risk relationship contributes to design more effective, context-based policies addressing the target of land resource conservation and adapting to specific territorial conditions (Briassoulis 2011). Use of administrative districts, such as municipalities, taken as policy-relevant spa- 
tial domains, allows a comprehensive investigation of context-based, ecological-economic interactions that are frequently demised in classical economic approaches and 'centralized', spatially implicit interpretative models (Cecchini et al. 2019). Additionally, municipalities are readable spatial units matching different socioeconomic information with ecological indicators derived from official statistics (Carlucci et al. 2018; Di Feliciantonio et al. 2018; Duvernoy et al. 2018). Based on these premises, the present study adopts an exploratory approach based on a geographically weighted regression (GWR), a statistical technique controlling for spatial structures that characterize the relationship between the SDI, taken as the dependent variable, and the ESAI, taken as the predictor (Ali et al. 2007). Being used extensively, GWRs estimate local regression models for each spatial domain in a given area, accounting for spatial dependence and heterogeneity (Fotheringham et al. 2002). A GWR specification for a given location $\mathrm{s}=1$ to $\mathrm{n}$, is:

$$
\mathrm{Y}(\mathrm{s})=\mathrm{X}(\mathrm{s}) \mathrm{B}(\mathrm{s})+\mathrm{e}(\mathrm{s})
$$

where $\mathrm{Y}(\mathrm{s})$ and $\mathrm{X}(\mathrm{s})$ are, respectively, the SDI and the ESAI scores, both measured at each location s (Italian municipalities), B(s) means the column vector of regression coefficients at location s, and e(s) is the random error at location s. Regression parameters estimated at each location by weighted least squares are spatially explicit, i.e., a function of $s$, a point within the geographical space of the study area (Anselin 2001). A Kernel spline function was adopted to calculate weights for the estimation of local regressions (Zambon et al. 2017). Limitations regarding the use of GWR only arise when drawing conclusions based on a reduced number of sample observations, which is not the case of this study (Rupasingha et al. 2004). Geographically weighted regressions were run using a spatial tool available in ArcGIS (Redwoods, CA, USA) software (release 10).

\section{Results}

Reflecting the role of local contexts in the analysis of sustainable development paths, the relationship between two composite indexes of desertification risk and sustainable development was investigated in 8101 Italian municipalities using a geographically weighted regression. The spatial distribution of both indexes was shown in Figure 1, evidencing a particularly heterogeneous context in both cases. On average, the composite index of sustainable development (SDI) was higher in Northern Italy and, partly, in Central Italy, decreasing more evidently in Southern Italy. The composite index of desertification risk (ESAI) followed the reverse pattern, although both indexes showed a marked heterogeneity across both Northern Italy and Southern Italy. The traditional divide in accessible, advanced and economically dynamic regions (Northern-Central Italy) and economically disadvantaged/remote regions (Southern Italy) is a stylized fact that is valid only at a very aggregate territorial scale. Considering local development at the scale of municipalities in Italy, North-South divides reduce and are basically hard to identify, while other gaps (urban-rural, coastal-inland) reinforce and influence substantially the geography of sustainable development and desertification risk. The heterogeneous distribution of both indicators across Italy justifies a refined and spatially explicit analysis of the relationship between the level of sustainable development and desertification risk.

A GWR provided local regression estimates of the relationship between SDI and ESAI with an adjusted $\mathrm{R}^{2}$ value for the global model reaching 0.65 . This coefficient indicates a sufficiently high goodness-of-fit of the spatial regression, confirming the appropriateness of a spatially explicit analysis of desertification risk and sustainable development at the local scale. Slope coefficients were estimated locally and illustrated in Figure 2 using two maps depicting the spatial distribution of municipalities with significantly negative regression coefficients (left) and significantly positive regression coefficients (right) at three significance levels $\left({ }^{*} 0.01<p<0.05 ;{ }^{* *} 0.001<p<0.01 ;{ }^{* * *} p<0.001\right)$. The relationship between SDI and ESAI was significant across the whole national territory, although the sign of the relationship was largely variable over space. A significantly negative relationship (i.e., the level of sustainable development was inversely related with desertification risk) 
was observed in Southern Italian regions, and more specifically in Campania, Western Basilicata and Apulia, Sicily and Northern Sardinia. These areas are the most exposed to land degradation in the country, based on the national classification developed in the National Action Plan to Combat Desertification (Italian NAP).
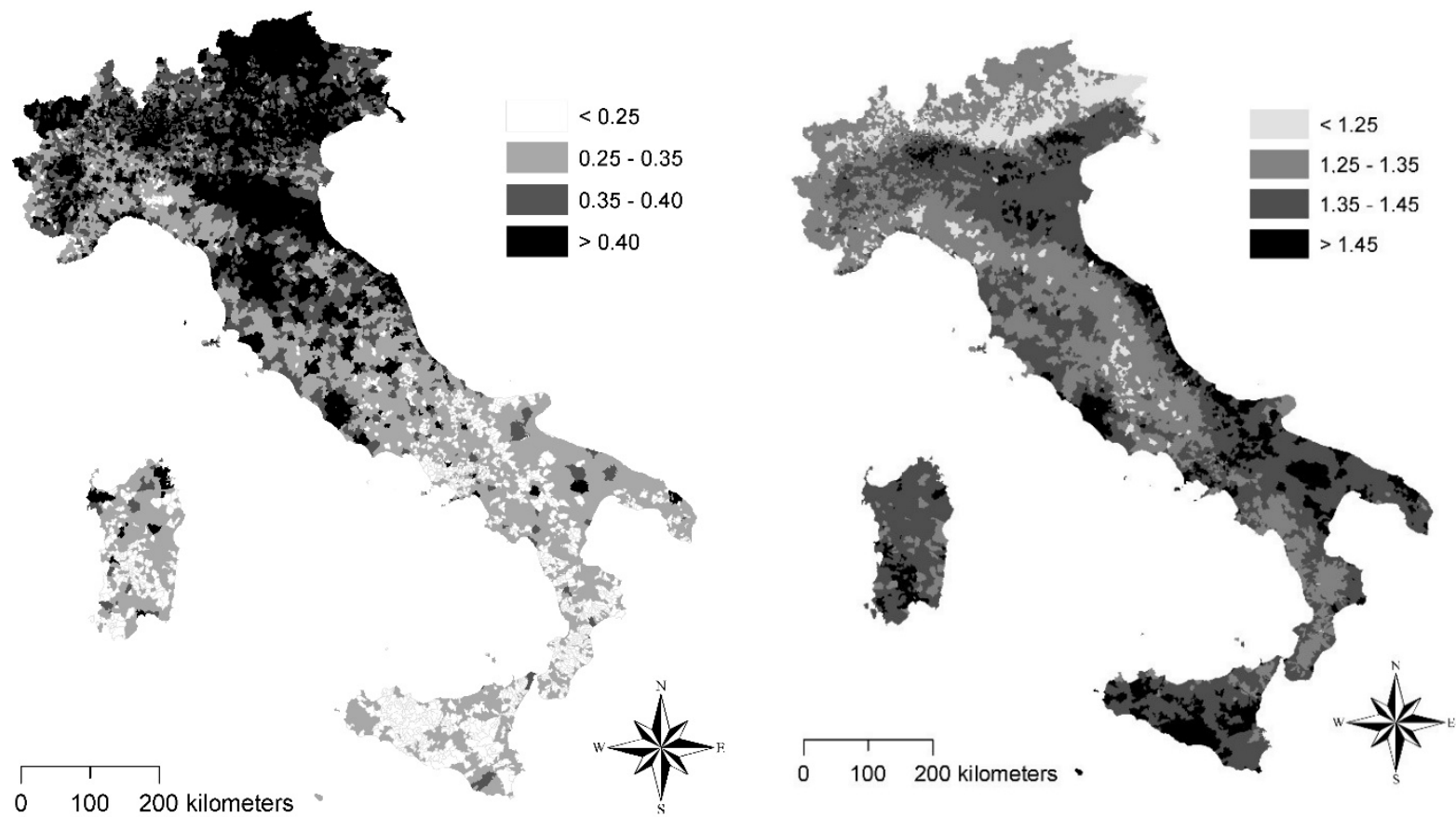

Figure 1. Left: Spatial distribution of a composite index of sustainable development (SDI) and, right: of a composite index of desertification risk (ESAI) in Italy.

An intense and positive relationship between sustainable development and desertification risk was reported for the rest of the Italian municipalities (apart from Sardinia, Eastern Sicily, and Central Apulia), especially those in Northern and Central Italy. This result suggests that, in such contexts, an increase in the level of sustainable development determines a side effect leading to a contemporary increase of desertification risk. This evidence is particularly stable over space in both Northern and Central Italy, with the only exception being a few districts in North-Eastern Veneto, Friuli, Trentino Alto Adige, and Aosta Valley. These areas are typically mountainous, with a moderate-low level of desertification risk, being classified as 'not affected' in the Italian NAP. The positive relationship between SDI and ESAI was also observed in some limited areas of Southern Italy (Central Calabria and Eastern Apulia). The most intense, positive correlation was observed in an inland district of Calabria (Sila mountains) that is less affected by land degradation because of favorable climate and moderately low human pressure.

Taken together, these results suggest how the relationship between sustainable development and desertification risk in Italy is particularly complex over space, despite the fact that an intense polarization in Northern-Central and Southern Italian regions exist as far as the sign of the relation itself. A significant association observed between the standardized (local) regression coefficient and the level of desertification risk in Italy (Spearman rank correlation test, $p<0.001, \mathrm{n}=8101$ ) confirms that the spatial interaction between sustainable development and desertification risk is context-sensitive. 

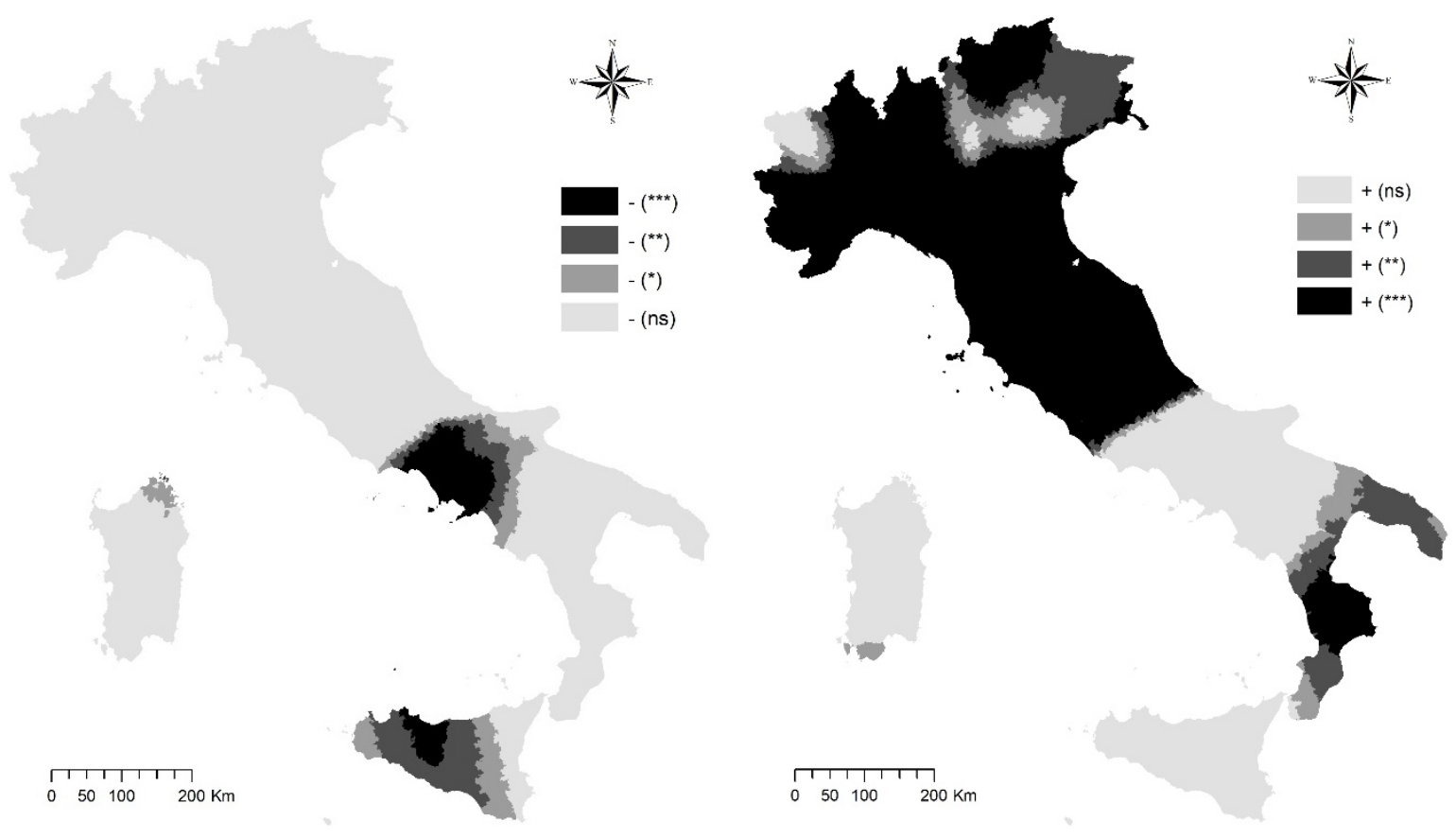

Figure 2. Results of a Geographically Weighted Regression for the relationship between a composite index of sustainable development (SDI) and a composite index of desertification risk (ESAI) in Italy; left: negative regression coefficients, right: positive regression coefficients. $\left({ }^{*} 0.01<p<0.05\right.$; ** $\left.0.001<p<0.01 ;{ }^{* * *} p<0.001\right)$.

\section{Discussion}

The intrinsic complexity of socioeconomic dynamics and the associated ecological processes is a challenge for both science and policy (Ronchi et al. 2002). Spatially explicit approaches were demonstrated to outline-better than more traditional, spatially implicit analyses-the appropriate context for sustainable development, the contribution of distinctive components (economy, society, demography) to sustainability, and the impact (both direct and indirect) of environmental degradation on sustainability targets (Booysen 2002; Danfeng et al. 2006; Malkina-Pykh and Pykh 2008; Bajocco et al. 2016). At the same time, the use of composite indices to measure sustainability is an opportunity to summarize complex concepts in concise measures quantifying spatial trends (Salvati and Zitti 2009). The present study uses a spatially explicit approach to investigate the intimate relationship between a composite index of sustainable development and a composite index of desertification risk, assuming that sustainability cannot be guaranteed in a local context with important imbalances in one pillar (economy, society, or environment). Integrated frameworks focusing on multiple factors of change are likely to be the most appropriate when investigating complex dynamics of sustainability and loss of natural resources at the local scale (Dumanski et al. 1998; Marston et al. 2005; Siche et al. 2008).

\subsection{The Importance of Spatially Explicit Evaluations of Sustainable Development}

Our approach, based on a geographically weighted regression, allows a direct comparison across municipalities with the aim at delineating environmental-economic performances among regions and geographical areas. By integrating multiple socioeconomic and ecological factors, and focusing on different priorities in national policies (Wilson and Juntti 2005), the evaluation model adopted two composite indexes of sustainable development and desertification risk in Italian municipalities. Composite indexes are meaningful when they improve knowledge of multidimensional concepts, as in the case of sustainable development and desertification risk (Yli-Viikari et al. 2007). Selecting proper indicators, integrating the information associated to those research dimensions, and delineating comparatively the spatial patterns of sustainable development and desertification risk are the 
constituting steps of our study (Salvati and Carlucci 2014). The evaluation approach was intended at a local (municipal/district) scale to provide policy makers and stakeholders with a simple assessment and spatial policy guidelines (Nader et al. 2008).

The empirical findings of this study suggest that environmental factors and mechanisms of land resource depletion may have a prominent role in promoting (or depressing) local sustainability (Danfeng et al. 2006). Use of elementary spatial units (municipalities/districts) sufficiently disaggregated and supposed to be relevant for spatial planning, is an original approach to the analysis of sustainable development, emphasizing the importance of local communities and the role of local districts in polarized regions/countries (Recanatesi et al. 2016). Unpredictable local actors' behaviors focusing on decision variables that are in turn shaped by broader socioeconomic forces may complicate the analysis of sustainable development paths (Antrop 2005; Hubacek and van den Bergh 2006; Bajocco et al. 2015). Regional disparities shape, at the same time, the impact local communities have on environmental dynamics contributing to sustainability, evidencing critical steps of the sustainability discourse when planning local development (Kok et al. 2004; Patel et al. 2007; Barbayiannis et al. 2011). Italy is a representative case in the Mediterranean basin because of a differential path of economic development in Northern (wealthier and advanced) and Southern (economically depressed) regions, in turn reflecting a polarized pattern of environmental sensitivity (Salvati and Zitti 2009). Delineating important divides in demographic and social structures as well as an imbalanced distribution of land resources, spatial disparities in Italy contribute to consolidate diverging models of local sustainability (Delfanti et al. 2016; Smiraglia et al. 2016; Zambon et al. 2017).

These results highlight two spatial relationships between sustainable development and desertification risk in Italy, being reflective of distinctive interactions observed in Northern/Central Italy and in a large part of Southern Italy (Recanatesi et al. 2016). A static interpretation of the negative relationship between SDI and ESAI in a large part of Southern Italy suggests how local contexts exposed to desertification risk are also characterized with a moderately low level of sustainable development. These findings document a traditional 'downward spiral' between environmental degradation and local development (Salvati and Zitti 2008), suggesting that endogenous growth factors alone cannot unlock the system moving it out of the 'spiral' (Egidi et al. 2021). Exogenous forces (policy measures) are required to bring it toward a truly sustainable growth path (Briassoulis 2011). Earlier studies have hypothesized a negative relationship between the risk of desertification and local development, also documenting a direct linkage between land degradation and economic contexts at risk of poverty and social degradation, mainly in developing countries (Wilson and Juntti 2005). Our results add to this research perspective, documenting a similar relationship even for a developed country like Italy.

\subsection{The Role of Strategic Policies in Desertification-Sustainable Development Nexus}

The positive relationship between the level of sustainable development and the risk of desertification in Northern/Central Italy, testifies the linkage existing between economic development and specific processes of environmental degradation, such as land degradation. In other words, economic growth, even along paths that adhere to the sustainability paradigm, cannot exclude a priori negative externalities on the environment (Kahuthu 2006). The results of the spatial regressive model highlight how the achievement of a certain level of sustainable development alone does not ensure the abatement of ecological degradation(Abu Hammad and Tumeizi 2012). These findings document the importance of the economic dimension of development in wealthier countries, suggesting that the pursuit of sustainable development is a multivariate target incorporating the abatement of ecological degradation (Khatun 2009). This target should be pursued through specific policy and planning strategies including subsidiary interventions and incentives for good practices at all intervention scales (Ronchi et al. 2002; Nader et al. 2008; Nourry 2008).

The two spatial models delineated above definitely reflect the different mechanisms underlying sustainable development and desertification risk in developed countries (Wilson 
and Juntti 2005), claiming for distinctive strategies and policy solutions (Safriel and Adeel 2008; Briassoulis 2011; Esposito et al. 2018). Although it correctly distinguishes between affected and unaffected areas, the Italian NAP should be updated with more recent studies that document how, even in structurally unaffected areas, degradation factors that trigger early desertification processes in limited areas are active (Zambon et al. 2017). In this sense, the positive linkage between local development and risk factors requires a specific policy intervention in non-affected regions (Central-Northern Italy). Spatially explicit analysis highlights the role of local territories (Colantoni et al. 2015), suggesting how any effective policy promoting true sustainable development in contexts more or less affected by desertification risk should be designed taking account of the environmental peculiarities and socioeconomic characteristics of the local context. These actions seem particularly pertinent in light of land degradation neutrality (LDN), defined as a given contextual state whereby the amount and quality of land resources, necessary to support ecosystem functions and services and enhance food security, remains stable or increases within specified temporal and spatial scales and ecosystems. Despite being strongly encouraged at different planning and operational scales-from supra-national (e.g., UNCCD) to localstrategies addressing LDN targets are still heterogeneous and mixed in most affluent economies and require additional information to be correctly designed and developed in specific socioeconomic contexts of Southern Europe (Smetanová et al. 2019; Pena et al. 2020; Al Sayah et al. 2021).

The originality of this study lies in the 'holistic' approach to sustainability supported with a spatially explicit analysis (Akbari et al. 2019). Results suggest how any debate about sustainable development strategies should be formulated (or re-formulated) based on the scope, administrative level, and nature of the intervention, considering the ecological context and local degradation processes as basic information to finely tune developmental strategies, environmental policy, and spatial planning. Since land mismanagement emerged as a striking result of income growth, economic, social, and environmental targets are considered jointly and coordinated in order to prevent land resource depletion. In this perspective, developing decision support systems based on spatial analysis of composite indicators is appropriate when delineating environmental and socioeconomic trends. An in-depth knowledge of local communities and the territorial characteristics of land exposed to degradation processes contributes to develop scenario modelling and integrated policies mitigating human pressure in ecologically fragile areas.

\section{Conclusions}

Our study adopts an extensive definition of sustainability as a multivariate attribute of local systems based on two interacting dimensions. Developing the approach proposed here with a diachronic perspective seems to be a meaningful tool to evaluate appropriateness, effectiveness, and timing of sustainable development policies implemented at the local scale. This may also document the intrinsic nexus between a spatially balanced sustainable development and ecological processes (largely variable across space) that require a more comprehensive investigation from regional to supra-national scales. Considering the latent interplay between environmental and socioeconomic forces, additional methodologies integrating official statistics and the empirical findings from remote sensing approaches seem to be particularly appropriate in this context with the aim at improving precision, reliability, spatio-temporal coverage and the regular update of relevant indicators, from both the ecological side and the social dimension. Since socioeconomic forces may influence the environmental context through non-linear paths, feedback interactions with exogenous variables should be more deeply investigated in future studies. Addressing this issue often requires a thorough recognition of the intrinsic economic value of soils, long-term investments in land quality and a mechanism through which these ameliorations can be transferred to farmers with appropriate incentives to reward sustainable land management. 
Supplementary Materials: The following supporting information can be downloaded at: https: //www.mdpi.com/article/10.3390/economies10020050/s1.

Author Contributions: Conceptualization, L.S. and A.C.; methodology, L.B. and G.E.; investigation, R.S. and G.P.; resources, G.Q. and A.C.; writing-original draft preparation, R.S. and L.S.; writingreview and editing, G.P. and G.E.; visualization, A.C. and L.B.; supervision, A.C. and G.P.; project administration, G.Q. and R.S.; funding acquisition, G.Q. All authors have read and agreed to the published version of the manuscript.

Funding: This research received no external funding.

Institutional Review Board Statement: Not applicable.

Informed Consent Statement: Not applicable.

Data Availability Statement: Not applicable.

Conflicts of Interest: The authors declare that they have no conflicts of interest.

\section{References}

Abu Hammad, Ahmad, and Abdulhlaeem Tumeizi. 2012. Land degradation: Socioeconomic and environmental causes and consequences in the eastern Mediterranean. Land Degradation \& Development 23: 216-26. [CrossRef]

Akbari, Morteza, Masoud Jafari Shalamzari, Hadi Memarian, and Atefeh Gholami. 2019. Monitoring desertification processes using ecological indicators and providing management programs in arid regions of Iran. Ecological Indicators 111: 106011. [CrossRef]

Akhtar-Schuster, Mariam, Lindsay C. Stringer, Alexander Erlewein, Graciela Metternicht, Sara Minelli, Uriel Safriel, and Stefan Sommer. 2017. Unpacking the concept of land degradation neutrality and addressing its operation through the Rio Conventions. Journal of Environmental Management 195: 4-15. [CrossRef] [PubMed]

Al Sayah, Mario J., Chadi Abdallah, Michel Khouri, Rachid Nedjai, and Talal Darwich. 2021. On the use of the Land Degradation Neutrality concept in mediterranean watersheds for land restoration and erosion counteraction. Journal of Arid Environments 188: 104465. [CrossRef]

Ali, Kamar, Mark D. Partridge, and M. Rose Olfert. 2007. Can Geographically Weighted Regressions Improve Regional Analysis and Policy Making? International Regional Science Review 30: 300-29. [CrossRef]

Anselin, Luc. 2001. Spatial Effects in Econometric Practice in Environmental and Resource Economics. American Journal of Agricultural Economics 83: 705-10. [CrossRef]

Antrop, Marc. 2005. Why landscapes of the past are important for the future. Landscape and Urban Planning 70: 21-34. [CrossRef]

Bajocco, Sofia, Antonella De Angelis, and Luca Salvati. 2012. A satellite-based green index as a proxy for vegetation cover quality in a Mediterranean region. Ecological Indicators 23: 578-87. [CrossRef]

Bajocco, Sofia, Eleni Dragoz, Ioannis Gitas, Daniela Smiraglia, Luca Salvati, and Carlo Ricotta. 2015. Mapping Forest Fuels through Vegetation Phenology: The Role of Coarse-Resolution Satellite Time-Series. PLoS ONE 10: e0119811. [CrossRef]

Bajocco, Sofia, Tomaso Ceccarelli, Daniela Smiraglia, Luca Salvati, and Carlo Ricotta. 2016. Modeling the ecological niche of long-term land use changes: The role of biophysical factors. Ecological Indicators 60: 231-36. [CrossRef]

Barbayiannis, Nick, K. Panayotopoulos, Demetrios Psaltopoulos, and Dimitris Skuras. 2011. The influence of policy on soil conservation: A case study from Greece. Land Degradation \& Development 22: 47-57. [CrossRef]

Barrett, Scott, and Kathryn Graddy. 2000. Freedom, growth, and the environment. Environment and Development Economics 5: 433-56. [CrossRef]

Benassi, Federico, Sirio Cividino, Pavel Cudlin, Ahmed Alhuseen, Giuseppe Ricciardo Lamonica, and Luca Salvati. 2020. Population trends and desertification risk in a Medi-terranean region, 1861-2017. Land Use Policy 95: 104626. [CrossRef]

Biasi, Rita, Elena Brunori, Daniela Smiraglia, and Luca Salvati. 2015. Linking traditional tree-crop landscapes and agro-biodiversity in Central Italy us-ing a database of typical and traditional products: A multiple risk assessment through a data mining analysis. Biodiversity and Conservation 24: 3009-31. [CrossRef]

Boardman, John, Jean Poesen, and Robert Evans. 2003. Socio-economic factors in soil erosion and conservation. Environmental Science $\mathcal{E}$ Policy 6: 1-6. [CrossRef]

Booysen, Frederik. 2002. An Overview and Evaluation of Composite Indices of Development. Social Indicators Research 59: 115-51. [CrossRef]

Boyce, James K. 1994. Inequality as a cause of environmental degradation. Ecological Economics 11: 169-78. [CrossRef]

Briassoulis, Helen. 2011. Governing desertification in Mediterranean Europe: The challenge of environmental policy integration in mul-ti-level governance contexts. Land Degradation and Development 22: 313-25. [CrossRef]

Carlucci, Margherita, Francesco Maria Chelli, and Luca Salvati. 2018. Toward a New Cycle: Short-Term Population Dynamics, Gentrification, and Re-Urbanization of Milan (Italy). Sustainability 10: 3014. [CrossRef]

Cavlovic, Therese A., Kenneth H. Baker, Robert P. Berrens, and Kishore Gawande. 2000. A Meta-Analysis of Environmental Kuznets Curve Studies. Agricultural and Resource Economics Review 29: 32-42. [CrossRef] 
Cecchini, Massimo, Ilaria Zambon, Antonella Pontrolfi, Rosario Turco, Andrea Colantoni, Anastasios Mavrakis, and Luca Salvati. 2019. Urban sprawl and the 'olive' landscape: Sustainable land management for 'crisis' cities. GeoJournal 84: 237-55. [CrossRef]

Cerdà, Artemio, Heuven Lavee, Antonio Romero-Díaz, James Hooke, and Luca Montanarella. 2010. Preface. Land Degradation E Development 21: 71-74. [CrossRef]

Chelleri, Lorenzo, Thorsten Schuetze, and Luca Salvati. 2015. Integrating resilience with urban sustainability in neglected neighborhoods: Challenges and opportunities of transitioning to decentralized water management in Mexico City. Habitat International 48 : 122-30. [CrossRef]

Chimeli, Ariaster B. 2007. Growth and the environment: Are we looking at the right data? Economics Letters 96: 89-96. [CrossRef]

Ciommi, Mariateresa, Francesco M. Chelli, Margherita Carlucci, and Luca Salvati. 2018. Urban Growth and Demographic Dynamics in Southern Europe: Toward a New Statistical Approach to Regional Science. Sustainability 10: 2765. [CrossRef]

Colantoni, Andrea, Carlotta Ferrara, Luigi Perini, and Luca Salvati. 2015. Assessing trends in climate aridity and vulnerability to soil degradation in Italy. Ecological Indicators 48: 599-604. [CrossRef]

Corbelle-Rico, Eduardo, Rafael Crecente-Maseda, and Inés Santé-Riveira. 2012. Multi-scale assessment and spatial modelling of agricultural land aban-donment in a European peripheral region: Galicia (Spain), 1956-2004. Land Use Policy 29: $493-501$. [CrossRef]

Danfeng, Sun, Richard Dawson, and Li Baoguo. 2006. Agricultural causes of desertification risk in Minquin, China. Journal of Environmental Management 79: 348-56. [CrossRef]

Dasgupta, Susmita, Kirk Hamilton, Kiran D. Pandey, and David Wheeler. 2006. Environment During growth: Accounting for governance and vulnerability. World Development 34: 1597-611. [CrossRef]

Delfanti, Lavinia, Andrea Colantoni, Fabio Recanatesi, Massimiliano Bencardino, Adele Sateriano, Ilaria Zambon, and Luca Salvati. 2016. Solar plants, environmental degradation and local socioeconomic contexts: A case study in a Mediterranean country. Environmental Impact Assessment Review 61: 88-93. [CrossRef]

Destek, Mehmet Akif, and Samuel Asumadu Sarkodie. 2019. Investigation of environmental Kuznets curve for ecological footprint: The role of energy and financial development. Science of the Total Environment 650: 2483-89. [CrossRef] [PubMed]

Di Feliciantonio, Cesare, Luca Salvati, Efthymia Sarantakou, and Kostas Rontos. 2018. Class diversification, economic growth and urban sprawl: Evidences from a pre-crisis European city. Quality \& Quantity 52: 1501-22. [CrossRef]

Dumanski, James, Walter Pettapiece, and Robert J. McGregor. 1998. Relevance of scale dependent approaches for integrating biophysical and socio-economic information and development of agroecological indicators. Nutrient Cycling in Agroecosystems 50: 13-22. [CrossRef]

Duvernoy, Isabelle, Ilaria Zambon, Adele Sateriano, and Luca Salvati. 2018. Pictures from the other side of the fringe: Urban growth and peri-urban agri-culture in a post-industrial city (Toulouse, France). Journal of Rural Studies 57: 25-35. [CrossRef]

Egidi, Gianluca, Giovanni Quaranta, Rosanna Salvia, Luca Salvati, Renata Včeláková, and Pavel Cudlín. 2021. Urban sprawl and desertification risk: Unraveling the latent nexus in a mediterranean country. Journal of Environmental Planning and Management 65: 441-60. [CrossRef]

Esposito, Piero, Fabrzio Patriarca, Luigi Perini, and Luca Salvati. 2016. Land degradation, economic growth and structural change: Evidences from Italy. Environment, Development and Sustainability 18: 431-48. [CrossRef]

Esposito, Piero, Fabrizio Patriarca, and Luca Salvati. 2018. Tertiarization and land use change: The case of Italy. Economic Modelling 71: 80-86. [CrossRef]

Ferrara, Agostino, Claire Kelly, Geoff A. Wilson, Angelo Nolè, Giuseppe Mancino, Sofia Bajocco, and Luca Salvati. 2016. Shaping the role of 'fast' and 'slow' drivers of change in forest-shrubland socio-ecological systems. Journal of Environmental Management 169: 155-66. [CrossRef]

Ferrara, Agostino, Constantinos Kosmas, Luca Salvati, Antonietta Padula, Giuseppe Mancino, and Angelo Nolè. 2020. Updating the MEDALUS-ESA Framework for Worldwide Land Degradation and Desertification Assessment. Land Degradation E Development 31: 1593-607. [CrossRef]

Fingleton, Bernard. 2016. Externalities, Economic Geography, and Spatial Econometrics: Conceptual and Modeling Developments. International Regional Science Review 26: 197-207. [CrossRef]

Fotheringham, A. Stewart, Chris Brunsdon, and Martin Charlton. 2002. Geographically Weighted Regression: The Analysis of Spatially Varying Relationships. Hoboken: Wiley, ISBN 978-0-471-49616-8.

Franceschi, Dina, and James R. Kahn. 2003. Beyond strong sustainability. International Journal of Sustainable Development E World Ecology 10: 211-20. [CrossRef]

Galeotti, Marzio. 2007. Economic growth and the quality of the environment: Taking stock. Environment, Development and Sustainability 9: 427-54. [CrossRef]

Gavalas, Vasilis S., Kostas Rontos, and Luca Salvati. 2014. Who Becomes an Unwed Mother in Greece? Sociodemographic and Geographical Aspects of an Emerging Phenomenon. Population, Space and Place 20: 250-63. [CrossRef]

Gidding, Bob, Bill Hopwood, and Geoff O'Brien. 2002. Environment, economy and society: Fitting them together into sustainable development. Sustainable Development 10: 187-96. [CrossRef]

Gisladottir, Gudrun, and Michael Stocking. 2005. Land degradation control and its global environmental benefits. Land Degradation $\mathcal{E}$ Development 16: 99-112. [CrossRef] 
Halbac-Cotoara-Zamfir, Rares, Andrea Colantoni, Enrico Maria Mosconi, Stefano Poponi, Simona Fortunati, Luca Salvati, and Filippo Gambella. 2020. From Historical Nar-ratives to Circular Economy: De-Complexifying the "Desertification" Debate. International Journal of Environmental Research and Public Health 17: 5398. [CrossRef]

Heidkamp, C. Patrick. 2008. A theoretical framework for a 'spatially conscious' economic analysis of environmental issues. Geoforum 39: 62-75. [CrossRef]

Helldén, Ulf, and Christian Tottrup. 2008. Regional desertification: A global synthesis. Global and Planetary Change 64: 169-76. [CrossRef]

Huang, Jianping, Guolong Zhang, Xiaodan Zhang, Yun Wei, Ruixia Guan, and Ruixia Guo. 2020. Global desertification vulnerability to climate change and human activities. Land Degradation \& Development 31: 1380-91.

Hubacek, Klaus, and Jeroen C.J. Mvan van den Bergh. 2006. Changing concepts of 'land' in economic theory: From single to multi-disciplinary ap-proaches. Ecological Economics 56: 5-27. [CrossRef]

Imeson, Anton. 2012. Desertification, Land Degradation and Sustainability. Chichester: Wiley.

Iosifides, Theodoros, and Theodoros Politidis. 2005. Socio-economic dynamics, local development and desertification in western Lesvos, Greece. Local Environment 10: 487-99. [CrossRef]

Kahuthu, Aler. 2006. Economic Growth and Environmental Degradation in a Global Context. Environment, Development and Sustainability 8: 55-68. [CrossRef]

Kairis, Orestis, Christos Karavitis, Luca Salvati, Aikaterini Kounalaki, and Kostas Kosmas. 2015. Exploring the Impact of Overgrazing on Soil Erosion and Land Degradation in a Dry Mediterranean Agro-Forest Landscape (Crete, Greece). Arid Land Research and Management 29: 360-74. [CrossRef]

Kairis, Orestis, Costas Karavitis, Anna Kounalaki, Luca Salvati, and Costas Kosmas. 2013. The effect of land management practices on soil erosion and land desertification in an olive grove. Soil Use and Management 29: 597-606. [CrossRef]

Karamesouti, Mina, Vassilis Detsis, Anna Kounalaki, Penny Vasiliou, Luca Salvati, and Costas Kosmas. 2015. Land-use and land degradation processes affecting soil resources: Evidence from a traditional Mediterranean cropland (Greece). Catena 132: 45-55. [CrossRef]

Khatun, Tahmina. 2009. Measuring environmental degradation by using principal component analysis. Environment, Development and Sustainability 11: 439-57. [CrossRef]

Kirkby, Mike. 2021. Desertification and development: Some broader contexts. Journal of Arid Environments 193: 104575. [CrossRef]

Kok, Kasper, Dale S. Rothman, and Mita Patel. 2004. Multi-scale narratives from an IA perspective: Part I. European and Mediterranean scenario development. Futures 38: 261-84. [CrossRef]

Kosmas, Costas, Marinos Tsara, Nikos Moustakas, and Costas Karavitis. 2003. Identification of indicators for desertification. Annals of Arid Zones 42: 393-416.

Kosmas, Costas, Mina Karamesouti, Kate Kounalaki, Vassilis Detsis, Penny Vassiliou, and Luca Salvati. 2016. Land degradation and long-term changes in agro-pastoral systems: An empirical analysis of ecological resilience in Asteroussia-Crete (Greece). Catena 147: 196-204. [CrossRef]

Maddison, David. 2006. Environmental Kuznets curves: A spatial econometric approach. Journal of Environmental Economics and Management 51: 218-30. [CrossRef]

Malkina-Pykh, Irina G., and Yuri A. Pykh. 2008. Quality-of-life indicators at different scales: Theoretical background. Ecological Indicators 8: 854-62. [CrossRef]

Marathianou, Michalis, Costas Kosmas, Stavros Gerontidis, and Vassilis Detsis. 2020. Land-use evolution and degradation in Lesvos (Greece): An historical approach. Land Degradation and Development 11: 63-73. [CrossRef]

Marston, Sallie A., John Paul Jones, and Keith Woodward. 2005. Human geography without scale. Transactions of the Institute of British Geographers 30: 416-32. [CrossRef]

Martínez-Valderrama, Jaime, Emilio Guirado, and Ferno Maestre. 2020. Unraveling Misunderstandings about Desertification: The Paradoxical Case of the Tabernas-Sorbas Basin in Southeast Spain. Land 9: 269. [CrossRef]

Munasinghe, Mohan. 1999. Is environmental degradation an inevitable consequence of economic growth: Tunneling through the environmental Kuznets curve. Ecological Economics 29: 89-109. [CrossRef]

Nader, Manal R., Bachir Abi Salloum, and Nadim Karam. 2008. Environment and sustainable development indicators in Lebanon: A practical municipal level approach. Ecological Indicators 8: 771-77. [CrossRef]

Niemeijer, David. 2002. Developing indicators for environmental policy: Data-driven and theory-driven approaches examined by example. Environmental Science \& Policy 5: 91-103. [CrossRef]

Nourry, Myriam. 2008. Measuring sustainable development: Some empirical evidence for France from eight alternative indicators. Ecological Economics 67: 441-56. [CrossRef]

Patel, Mita, Kasper Kok, and Dale S. Rothman. 2007. Participatory scenario construction in land use analysis: An insight into the experiences created by stakeholder involvement in the Northern Mediterranean. Land Use Policy 24: 546-61. [CrossRef]

Pena, Selma Beatriz, Maria Manuela Abreu, Manuela Raposo Magalhães, and Nuno Cortez. 2020. Water erosion aspects of land degradation neutrality to landscape planning tools at national scale. Geoderma 363: 114093. [CrossRef]

Perrin, Coline, Brigitte Nougarèdes, Laura Sini, Paola Branduini, and Luca Salvati. 2018. Governance changes in peri-urban farmland protection following decentralisation: A comparison between Montpellier (France) and Rome (Italy). Land Use Policy 70: 535-46. [CrossRef] 
Portnov, Boris A., and Uriel N. Safriel. 2004. Combating desertification in the Negev: Dryland agriculture vs. dryland urbanization. Journal of Arid Environments 56: 659-80. [CrossRef]

Recanatesi, Fabio, Matteo Clemente, Efstathios Grigoriadis, Flavia Ranalli, Marco Zitti, and Luca Salvati. 2016. A Fifty-Year Sustainability Assessment of Italian Agro-Forest Districts. Sustainability 8: 32. [CrossRef]

Rodrigo-Comino, Jesús, José María Senciales, Artemi Cerdà, and Eric C. Brevik. 2018. The multidisciplinary origin of soil geography: A review. Earth-Science Reviews 177: 114-23. [CrossRef]

Rodrigo-Comino, Jesús, Rosanna Salvia, Gianluca Egidi, Luca Salvati, Antonio Giménez-Morera, and Giovanni Quaranta. 2021. Desertification and Degradation Risks vs Poverty: A Key Topic in Mediterranean Europe. Cuadernos de Investigación Geográfica. [CrossRef]

Romm, Jack. 2011. Desertification: The next dust bowl. Nature 478: 450-51. [CrossRef]

Ronchi, Edo, Antonio Federico, and Federico Musmeci. 2002. A system oriented integrated indicator for sustainable development in Italy. Ecological Indicators 2: 197-210. [CrossRef]

Rontos, Kostas, Efstathios Grigoriadis, Adele Sateriano, Maria Syrmali, Ioannis Vavouras, and Luca Salvati. 2016. Lost in protest, found in segregation: Divided cities in the light of the 2015 "Oxı" referendum in Greece. City, Culture and Society 7: 139-48. [CrossRef]

Rupasingha, Anil, Stephan J. Goetz, David L. Debertin, and Angelo Pagoulatos. 2004. The environmental Kuznets curve for US counties: A spatial econometric analysis with extensions. Papers in Regional Science 83: 407-24. [CrossRef]

Safriel, Uriel, and Zafar Adeel. 2008. Development paths of drylands: Thresholds and sustainability. Sustainability Science 3: 117-23. [CrossRef]

Salvati, Luca, and Marco Zitti. 2007. Territorial disparities, natural resource distribution, and land degradation: A case study in southern Europe. GeoJournal 70: 185-94. [CrossRef]

Salvati, Luca, and Marco Zitti. 2008. Assessing the impact of ecological and economic factors on land degradation vulnerability through multiway analysis. Ecological Indicators 9: 357-63. [CrossRef]

Salvati, Luca, and Marco Zitti. 2009. Substitutability and weighting of ecological and economic indicators: Exploring the importance of various components of a synthetic index. Ecological Economics 68: 1093-99. [CrossRef]

Salvati, Luca, and Margherita Carlucci. 2014. A composite index of sustainable development at the local scale: Italy as a case study. Ecological Indicators 43: 162-71. [CrossRef]

Salvati, Luca, and Pere Serra. 2016. Estimating Rapidity of Change in Complex Urban Systems: A Multidimensional, Local-Scale Approach. Geographical Analysis 48: 132-56. [CrossRef]

Salvati, Luca, Marco Petitta, Tomaso Ceccarelli, Luigi Perini, Federica Di Battista, and Maria Elisa Venezian Scarascia. 2008. Italy's renewable water resources as estimated on the basis of the monthly water balance. Irrigation and Drainage 57: 507-15. [CrossRef]

Salvati, Luca, Roberta Gemmiti, and Luigi Perini. 2012. Land degradation in Mediterranean urban areas: An unexplored link with planning? Area 44: 317-25. [CrossRef]

Sannigrahi, Srikanta, Qi Zhang, Francesco Pilla, Pawan Kumar Joshi, Bidroha Basu, Saskia Keesstra, P. S. Roy, Ying Wang, Paul C. Sutton, Suman Chakraborti, and et al. 2020. Responses of ecosystem services to natural and anthropogenic forcings: A spatial regression based assessment in the world's largest mangrove ecosystem. Science of The Total Environment 715: 137004. [CrossRef]

Siche, Raul, Francisco Agostinho, Ermanno Ortega, and Antonio Romeiro. 2008. Sustainability of nations by indices: Comparative study between environmental sustainability index, ecological footprint and the emergy performance indices. Ecological Economics 66: 628-37. [CrossRef]

Smetanová, Anna, Stéphane Follain, Mélodie David, Rossano Ciampalini, Damien Raclot, Arm Crabit, and Yves leBissonnais. 2019. Landscaping compromises for land degradation neutrality: The case of soil erosion in a Mediterranean agricultural landscape. Journal of Environmental Management 235: 282-92. [CrossRef] [PubMed]

Smiraglia, Daniela, Tomaso Ceccarelli, Sofia Bajocco, Luca Salvati, and Luigi Perini. 2016. Linking trajectories of land change, land degradation processes and ecosystem services. Environmental Research 147: 590-600. [CrossRef] [PubMed]

Sterk, Geert, and Jetse J. Stoorvogel. 2020. Desertification-Scientific Versus Political Realities. Land 9: 156. [CrossRef]

Tschakert, Petra. 2007. Views from the vulnerable: Understanding climatic and other stressors in the Sahel. Global Environmental Change 17: 381-96. [CrossRef]

Wang, Xunming, Fahu Chen, and Zhibao Dong. 2006. The relative role of climatic and human factors in desertification in semiarid China. Global Environmental Change 16: 48-57. [CrossRef]

Warner, Koko. 2010. Global environmental change and migration: Governance challenges. Global Environmental Change 20: 402-13. [CrossRef]

Wessels, Karel J., Stephen D. Prince, John Malherbe, John Small, Peter E. Frost, and Daniel Van Zyl. 2007. Can human-induced land degradation be distinguished from the effects of rainfall variability? A case study in South Africa. Journal of Arid Environments 68 : 271-97. [CrossRef]

Wilson, Geoffrey A., and Mari Juntti. 2005. Unravelling Desertification. Wageningen: Wageningen University Press.

Wolff, Sean, Elizabeth Adrian Schrammeijer, Carl J. Schulp, and Peter H. Verburg. 2018. Meeting global land restoration and protection targets: What would the world look like in 2050? Global Environmental Change 52: 259-72. [CrossRef]

Yamamoto, Daisaku. 2008. Scales of regional income disparities in the USA, 1955-2003. Journal of Economic Geography 8: 79-103. [CrossRef] 
Yli-Viikari, Alli, Rob Hietala-Koivu, Erwin Huusela-Veistola, Tulli Hyvonen, Paul Perala, and Eddi Turtola. 2007. Evaluating agrienvironmental indica-tors (AEIs)—Use and limitations of international indicators at national level. Ecological Indicators 7: 150-63. [CrossRef]

Zambon, Ilaria, Andrea Colantoni, Margherita Carlucci, Nathan Morrow, Adele Sateriano, and Luca Salvati. 2017. Land quality, sustainable development and environmental degradation in agricultural districts: A computational approach based on entropy indexes. Environmental Impact Assessment Review 64: 37-46. [CrossRef]

Zambon, Ilaria, Carlotta Ferrara, Anna Benedetti, and Luca Salvati. 2018. Soil matters? A multivariate analysis of socioeconomic constraints to urban expansion in Mediterranean Europe. Ecological Economics 146: 173-83. [CrossRef]

Zhou, Penn, B. Wi Ang, and Du Q. Zhou. 2010. Weighting and Aggregation in Composite Indicator Construction: A Multiplicative Optimization Approach. Social Indicators Research 96: 169-81. [CrossRef]

Zuindeau, Bertrand. 2007. Territorial Equity and Sustainable Development. Environmental Values 16: 253-68. [CrossRef] 